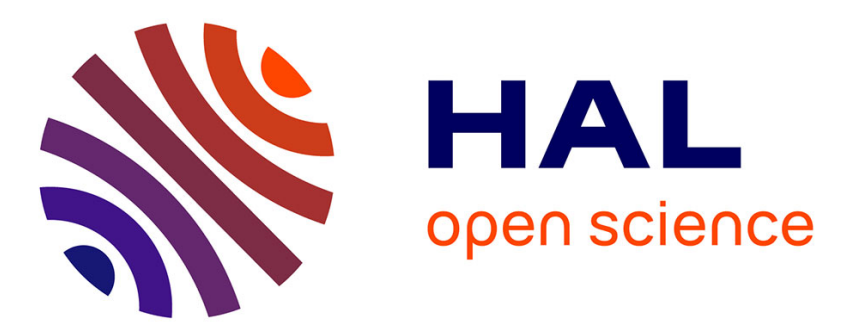

\title{
Synthesis and characterisation of bio-based polyester materials from vegetable oil and short to long chain dicarboxylic acids
}

\author{
Maëlle Gobin, Patrick Loulergue, Jean-Luc Audic, Loïc Lemiègre
}

\section{To cite this version:}

Maëlle Gobin, Patrick Loulergue, Jean-Luc Audic, Loïc Lemiègre. Synthesis and characterisation of bio-based polyester materials from vegetable oil and short to long chain dicarboxylic acids. Industrial Crops and Products, 2015, 70, pp.213-220. 10.1016/j.indcrop.2015.03.041 . hal-01134645

HAL Id: hal-01134645

https://hal-univ-rennes1.archives-ouvertes.fr/hal-01134645

Submitted on 11 Mar 2016

HAL is a multi-disciplinary open access archive for the deposit and dissemination of scientific research documents, whether they are published or not. The documents may come from teaching and research institutions in France or abroad, or from public or private research centers.
L'archive ouverte pluridisciplinaire HAL, est destinée au dépôt et à la diffusion de documents scientifiques de niveau recherche, publiés ou non, émanant des établissements d'enseignement et de recherche français ou étrangers, des laboratoires publics ou privés. 


\section{Synthesis and characterisation of bio-based polyester materials}

\section{2 from vegetableoil and short to long chain dicarboxylic acids.}

3 Maëlle Gobin, ${ }^{a, b}$ Patrick Loulergue, ${ }^{a, b}$ Jean-Luc Audic, ${ }^{* a, b}$ and Lö̈c Lemiègre ${ }^{* a, b}$

4

a) Ecole Nationale Supérieure de Chimie de Rennes, CNRS, UMR 6226, 11 allée de Beaulieu, CS 50837, 35708

Rennes Cedex 7, France.

b) Université Européenne de Bretagne, France.

* Corresponding author. Tel. : +33223238160 ; Fax. +33223238199

E-mail adress: jean-luc.audic@univ-rennes1.fr

Abstract

Polyester-type polymers were efficiently prepared from broccoli seed oil and severalcarboxylic diacids. The polyesters were prepared through a simple two-step process including oxidation of the insaturations to oxiranes followed by ring opening with dicarboxylic acids under basic conditions. Eight polymer materials derived from different fatty diacids (from 5C to 16C) and an aromatic diacid were prepared and characterised. Rubber-type crosslinked biobased materials exhibited low Tg values comprised between -5 and $+5^{\circ} \mathrm{C}$ depending on the diacid type and length. These materials could find applications as they are or as plasticizer when blended with other polymers.

Keywords: Bio-based polyesters; epoxidation; epoxidized vegetable oil; broccoli seed oil

\section{Introduction}

The production of bio-based material is an increasing field of research that aims

24 to replace non-renewable sourced polymers.(Belgacem and Gandini, 2008; Biermann et 25 al., 2011; Chernykh et al., 2013; Meier, 2014; Meier et al., 2007; Montero de Espinosa 
and Meier, 2011; Mutlu and Meier, 2010; Stempfle et al., 2014; Xia et al., 2013) Vegetable oils are remarkable renewableresourcesparticularly abundant and cheap. Among them soybean oil is the subject of numerous research topics dealing with applications in polymer material. Indeed, soybean oil finds applications as lubricant, plasticizer or as other types of additives for polymer materials.(Altuna et al., 2011; Chernykh et al., 2013; Montero de Espinosa et al., 2014)Few examples describe also the use of vegetable oil for the preparation of polymer material through direct polymerisation of modified oils.(Maisonneuve et al., 2013; Stemmelen et al., 2011; Tan and Chow, 2010; Winkler and Meier, 2014; Yang et al., 2014)Usually, strategies developed so far for polymerisation of soybean or linseed oils involved multistep triglyceride modification ended by the key polymerisation step.(Biermann et al., 2011; Ma et al., 2013; Stempfle et al., 2014)The most promisingstrategiesinvolve shorter processesmainly based on anhydride-curing(España et al., 2012; Espinoza-Perez et al., 2011; Ručigaj et al., 2014; Samper et al., 2012) or acid-curing(Shogren et al., 2004; Shogren, 1999) of epoxidised vegetable oil. The present researchwork focuseson this field with threemain goals: 1) Finding new non-food applicationsfor vegetable oils, 2) Developinga polymerisation process leading topotentially biodegradable(Shogren et al., 2004; Shogren, 1999; Yang et al., 2014)polyester-type materialscompatible with the use ofcuring agents of various structures and 3) Determine the influence of the structure of the curing agent used in the polymerisation process. Our choice towards broccoli seed oil (BO) showed up several advantages. This oil is a by-productproducedbyan extraction process of the food complement industry.(Audic et al., 2014)Its production is actually about 2 tons per year but it could rapidly increase up to 20 tons per year in a near future. The broccoli seed oil is useless for human food industries considering its high erucic acid content (39\%). Thus, there is no ethical issue to use such broccoli oil in non-food applications.Broccoli 
51 seed oil is also particularly richin diunsaturated fatty chains such as linoleic and 52 linolenic acid (22\%); in addition it contains an average of 3.9double bonds per

53 triglycerides as determined by NMR in a previous paper.(Audic et al., 2014)

54 The polymerisation process described hereafter involves a two-step procedure: a 55 classical oxidation of the double bonds to epoxides and crosslinking by epoxide-opening with dicarboxylic diacids in basic media. Diacids were preferred to anhydrides because of their high availability at low cost and in various molecular structures. Indeed several carboxylic diacids were evaluated, 7 fatty diacids (C5, C6, C8, C10, C12, C14, C16) and 1 aromatic diacid (o-phenylene diacetic acid). The efficiency of the chemical reaction involved in the polyester synthesis, i. e. the ring opening reaction of oxirane with carboxylic acid was confirmed by NMR and ATR-FTIR analyses.Corresponding polymer materials were characterised by DMA (Dynamic Mechanical Analysis)demonstrating the potential of these polyester materials and determining the influence of the nature of the diacid (length, structure).

\section{Material and methods.}

\subsection{Synthesis.}

All reagents and solvents were used directly from the supplier without further purification unless noted. Nuclear magnetic resonance spectra were recorded at 400 $\mathrm{MHz}\left({ }^{1} \mathrm{H}\right)$ and $100 \mathrm{MHz}\left({ }^{13} \mathrm{C}\right)$. For $\mathrm{CDCl}_{3}$ solutions, the chemical shifts $(\delta)$ are reported as parts per million (ppm) referenced to the appropriate residual solvent peak. Coupling constants are reported in Hertz (Hz). Data are reported as follows: chemical shift (multiplicity, coupling constants where applicable, number of hydrogen atoms, attribution). Abbreviations are as follows: $s$ (singlet), $d$ (doublet), $t$ (triplet), $q$ (quartet), $d d$ (doublet of doublet), $d t$ (doublet of triplet), $m$ (multiplet), bs (broad singlet). The NMR peak assignments were determined from 2D NMR experiments such as COSY, 
HSQC, HMBC. Mass spectra were performed on a MS-ESI spectrometer and are reported as $\mathrm{m} / \mathrm{z}$. Masses are reported for the molecular ion $[\mathrm{M}+\mathrm{Na}]^{+}$.

\subsubsection{Epoxidized Broccoli seed oil.}

BO (300 g, $0.32 \mathrm{~mol}, 1$ equiv.), toluene (1.4 L) and formic acid (24 mL, $0.64 \mathrm{~mol}, 2$ equiv.) were mixed into a well-stirred reactor. Hydrogen peroxide (35\% wt in water) (143 mL, $1.91 \mathrm{~mol}, 6$ equiv.) was added dropwise to the reaction mixture at $50^{\circ} \mathrm{C}$. The reaction mixture was kept at the same temperature and monitored by MS-ESI. After 25h, the aqueous phase was extracted twice with toluene and the combined organic phases were dried $\left(\mathrm{MgSO}_{4}\right)$. The solvent was then evaporated under reduced pressure affording the EBO (319 g, 99\%). ${ }^{1} \mathrm{H}$ NMR ( $\left.\mathrm{CDCl}_{3}, 400 \mathrm{MHz}\right), \delta(\mathrm{ppm})$ 0.79-1.01 (m, 9H, $\left.\mathrm{CH}_{3}\right), 1.18-$ $1.77\left(\mathrm{~m}, 86 \mathrm{H}, \mathrm{CH}_{2}\right), 2.22-2.27\left(\mathrm{~m}, 6 \mathrm{H}, \mathrm{CH}_{2}-\mathrm{C}=0\right), 2.82-3.15(\mathrm{~m}, 7.8 \mathrm{H}$ (3.9 epoxides per/molecule), epoxides), 4.07 (dd, $J=5.9,11.9 \mathrm{~Hz}, 2 \mathrm{H}, \mathrm{CH} 2-0$ ), 4.22 (dd, $J=4.4,11.9 \mathrm{~Hz}$, $\left.\mathrm{CH}_{2}-\mathrm{O}\right), 5.17-5.22(\mathrm{~m}, 1 \mathrm{H}, \mathrm{CH}-\mathrm{O}) ;{ }^{13} \mathrm{C} \mathrm{NMR}\left(\mathrm{CDCl}_{3}, 100 \mathrm{MHz}\right), \delta(\mathrm{ppm}) 14.0\left(\mathrm{CH}_{3}\right), 22.6$ $\left(\mathrm{CH}_{2}\right), 24.8\left(\mathrm{CH}_{2}\right), 26.6\left(\mathrm{CH}_{2}\right), 27.9\left(\mathrm{CH}_{2}\right), 28.9-29.7\left(\mathrm{CH}_{2}\right), 31.9\left(\mathrm{CH}_{2}\right), 34.0\left(\mathrm{CH}_{2}-\mathrm{C}=\mathrm{O}\right)$, 54.1 (epoxides), 56.7-57.2 (epoxides), $62.1\left(\mathrm{CH}_{2}-\mathrm{O}\right), 68.9$ (CH-O), 172.8-173.3 (C=0); MS-ESI $m / z[\mathrm{M}+\mathrm{Na}]^{+}:$927.8, 941.8, 955.8, 969.8, 983.8, 997.8, 1011.8, 125.8, 1039.8, 1053.8, 1067.9, 1081.9, 1095.8.

\subsubsection{Reaction of EBO with benzoic acid.}

EBO (1.0 g, $1.0 \mathrm{mmol}, 1$ equiv.) was dissolved in toluene (7 mL). Benzoic acid (244 mg, 2.0 mmol, 2 equiv.) and MeONa (5.4 mg, $0.1 \mathrm{mmol}, 0.1$ equiv.) were added and the reaction mixture was heated to $110^{\circ} \mathrm{C}$. After $96 \mathrm{~h}$, AcOEt $(10 \mathrm{~mL})$ was added and the reaction mixture was washed with $\mathrm{NaOH} 1 \mathrm{M}(2 \times 10 \mathrm{~mL})$ and $\mathrm{HCl} 1 \mathrm{M}(10 \mathrm{~mL})$. The organic phase was dried over $\mathrm{MgSO}_{4}$ and the solvents were removed under reduced pressure. The product was obtained as a yellow oil (1.2 g) with a benzoic acid incorporation of 1.35 per molecule. ${ }^{1} \mathrm{H}$ NMR $\left(\mathrm{CDCl}_{3}, 400 \mathrm{MHz}\right), \delta(\mathrm{ppm}), 0.77-0.85(\mathrm{~m}$, 
101

102

103

104

105

106

107

108

109

110

111

112

113

114

115

116

117

118

119

120

121

122

123

124

125

$9 \mathrm{H}) ; 0.97-1.74(m, 95 \mathrm{H}) ; 2.22-2.28(m, 6 \mathrm{H}) ; 2.83-3.13(m, 3.16 \mathrm{H}) ; 3.33-3.50(m$, $0.42 \mathrm{H}) ; 3.53-3.64(m, 1.11 \mathrm{H}) ; 3.73-4.02(m, 0.49 \mathrm{H}) ; 4.06(d d, \mathrm{~J}=5.9 \mathrm{~Hz}, \mathrm{~J}=11.6 \mathrm{~Hz}, 2 \mathrm{H})$; $4.21(d d, \mathrm{~J}=4.4 \mathrm{~Hz}, \mathrm{~J}=11.6 \mathrm{~Hz}, 2 \mathrm{H}) ; 5.02(m, 1.15 \mathrm{H}) ; 5.17(p, \mathrm{~J}=5.2 \mathrm{~Hz}, 1 \mathrm{H}) ; 5.40-5.49(m$, $0.36 \mathrm{H}) ; 7.38(t, \mathrm{~J}=7.2 \mathrm{~Hz}, 3.2 \mathrm{H}) ; 7.50(t, \mathrm{~J}=7.2 \mathrm{~Hz}, 1.6 \mathrm{H}) ; 7.98(d, \mathrm{~J}=7.6 \mathrm{~Hz}, 3.2 \mathrm{H}) ;{ }^{13} \mathrm{C} \mathrm{NMR}$ $\left(\mathrm{CDCl}_{3}, 100 \mathrm{MHz}\right), \delta$ (ppm) 14.2, 21.0, 22.5-22.7, 24.8, 25.3, 25.5, 26.6, 27.8, 29.0-29.7, $30.7,31.8,33.7,34.0,34.1,54.2,54.3,57.2,60.4,62.1,68.9,72.7,128.4,129.7,130.0$, 133.0, 165.9, 166.4, 172.8, 173.3; MS-ESI $m / z[\mathrm{M}+\mathrm{Na}]^{+}: 927.8,941.8,955.8,969.8$, 983.8, 997.8, 1011.8, 1025.8, 1039.8, 1049.8, 1053.8, 1063.8, 1067.9, 1077.8, 1081.8, 1091.8, 1095.8, 1105.8, 1119.8, 1133.8, 1147.8, 1161.8, 1171.8, 1175.8, 1185.8, 1189.8, 1199.8, 1203.8, 1213.8, 1217.8, 1227.8, 1241.8, 1255.8, 1283.8, 1297.8, 1311.8, 1325.8, 1339.8.

\subsubsection{General Procedure for the reaction of EBO with diacid.}

EBO (3.0 g, 3.0 mmol, 1 equiv.), diacid (6.0 mmol, 2 equiv.) and MeONa (16 mg, $0.3 \mathrm{mmol}, 0.1$ equiv.) were homogenised at $120^{\circ} \mathrm{C}$ or at the melting temperature of the diacid. The reaction mixture was poured into an aluminium mould. The aluminium mould was then kept at the same temperature into an oven for $16 \mathrm{~h}$. The sample was then characterised by ATR-FTIR and DMA.

\subsection{Characterisation of polymer materials}

\subsubsection{ATR-FTIR.}

For IR spectroscopy a Perkin-Elmer Spectrum 100 system infrared spectrometer was used in attenuated total reflectance (ATR) mode using a DTGS detector $\left(4 \mathrm{~cm}^{-1}\right.$ resolution) with the spectral range of $650-4000 \mathrm{~cm}^{-1}$. In these measurements 15 scans were applied and the data were collected and analysed using the Spectrum ES 5.0 software. The sample is placed onto the surface of a diamond prism and the infrared radiation is collected after total reflection from the diamond-sample interface. 


\subsubsection{DMA.}

The viscoelastic properties of the cured films were measured with a DMA instrument (Q800, TA Instruments). Rectangular specimens, $18 \mathrm{~mm}$ in length, $13 \mathrm{~mm}$ in width and $2 \mathrm{~mm}$ in thickness, were prepared. The measurements were taken in single cantilever mode at a frequency of $1 \mathrm{~Hz}$ and at deformation amplitude of $20 \mu \mathrm{m}$. The temperature ranged from -100 to $100^{\circ} \mathrm{C}$ at scanning rate of $3^{\circ} \mathrm{C} . \mathrm{min}^{-1}$. The storage modulus (E'), loss modulus (E') and loss factor $(\tan \delta)$ of the cured films were measured as a function of the temperature.

\section{Results and discussion.}

\subsection{Epoxidized broccoli seed oil (EBO)}

The epoxidation of the broccoli seed oil (BO) has been described by our research group in a previous paper.(Audic et al., 2014)It follows a classical procedure involving the in situ formation of performic acid from formic acid and hydrogen peroxide that carried out the epoxidation of the 3.9 double bonds of the triglyceride in toluene (Scheme 1). We further optimised the oxidation process reducing the equivalencies of hydrogen peroxide(6 equiv./BO) and catalytic formic acid (2 equiv./BO). The reaction mixture is kept at $50^{\circ} \mathrm{C}$ for $24 \mathrm{~h}$ to reach a complete epoxidation as demonstrated by MS and NMR monitoring.

\subsection{Model reaction with a monoacid}

The so-formed epoxidised broccoli seed oil (EBO) was then ready to react with carboxylic acid functions through an epoxide-opening mechanism. This reaction was first evaluated with a monoacid model for establishing the best reaction conditions in terms of reactivity and reduction of side reactions. The EBO was put in reaction with benzoic acid in the presence of a catalyst at $100^{\circ} \mathrm{C}$ (Scheme 2). A bronsted acid ( $p$ toluene sulfonic acid, PTSA), a lewis acid $\left(\mathrm{ZnCl}_{2}\right)$ and a base (MeONa) were evaluated 
151 and the results are gathered in table 1 . NMR analysis permitted to follow both the 152 formation of the new ester bonds and the consumption of the epoxides.

153 When using 4 equivalents of benzoic acid, the bronsted acid gave in $4 \mathrm{~h}$ (Entry 1 ) the best 154 conversion in ester derivative (0.40) compared to the lewis acid (Entry 2, 0.30) and the 155 MeONa (Entry 3, 0.20). Concerning the selectivity of the reaction, the sum of ester 156 functions formed and of the remaining epoxide should correspond to the original 157 number of epoxides (3.9) if the desired ester linkage formation is the sole reaction. 158 Otherwise all extra-consumed epoxides result from side reactions. This criterion in $159 \mathrm{mind}$, the $\mathrm{ZnCl}_{2}$ is considered as the worst catalyst and $\mathrm{MeONa}$ as the best onepromoting 160 almost no side reaction. Increasing the reaction time to $24 \mathrm{~h}($ Entry $4,5,6)$ confirmed the 161 tendency of PTSA to perform side reactions instead of the formation of ester functions 162 both in the presence of 2 or 4 equivalents of benzoic acid. Finally MeONa was found to 163 favour the formation of ester linkages instead of other side reactions. The best results 164 were obtained with MeONa. The use of only 0.1 equiv. of catalyst in the presence of 2 165 equiv. of benzoic acid provided in $24 \mathrm{~h}$ an average of ester functions of 1.35 (maximum of 166 2) and 2.58 remaining epoxides, corresponding to a conversion of $68 \%$. It is noteworthy 167 that the catalytic amount of MeONa did not lead to methanolysis of the triglyceride as 168 observed on the ${ }^{1} \mathrm{H}$ NMR spectra (fig. 1). The acid-base reaction between MeONa and the 169 benzoic acid is in fact faster than the alcoholysis.

170 Side reactionswere noticed when using acidic catalysts. EBO dimers and trimers were 171 observed on SEC chromatograms(data not shown). Their formation was correlatedto the 172 formation of ether linkages between triglycerides as determined by ${ }^{1} \mathrm{H}$ NMR 173 experiments. Other research groups dealing with other epoxidized vegetable oils have 174 already describedsuch oligomerisation side reactions.(Shogren, 1999) Note that this 175 acid promoted etherification is also observed in the absence of carboxylic acid. 
176 Compared to these previous works, the reaction conditions described herein the 177 presence of catalytic MeONa provide an advantageous esterification process without 178 side reaction.

\subsection{Crosslinking with glutaric acid as model dicarboxylic acid}

The best reaction conditions obtained with benzoic acid were adapted to the within the EBO being enough to promote a homogeneous crosslinking of the triglycerides.

As a starting polymerisation experiment glutaric acid and EBOwere engaged. Impacts of the reaction temperature (Table 2, Entries 1-6) and the diacid/EBO ratio (Table 2, Entries 7-12) after 4 or $16 \mathrm{~h}$ of heating were evaluated. Reaction mixtures incorporating an EBO/glutaric acid molar ratio 1:2 (i.e. $\mathrm{COOH} /$ epoxide ratio 1:1) were placed at $60,80,100,120,140,160{ }^{\circ} \mathrm{C}$ in the presence of 0.1 equiv. of MeONa. After $4 \mathrm{~h}$, each sample presented different appearanceranging from colourless liquid to brown hard materials. This study at variable temperature led to the following conclusions:the reaction needs to be performed at temperature over $80^{\circ} \mathrm{C}$ and a

193 suitablepolymerisationin 4 his obtained at $120^{\circ} \mathrm{C}$, leading to a yellowish translucent 194 polymer. It is noteworthy that this temperature permitted to fully melt the glutaric acid $195\left(\mathrm{Mp}=98^{\circ} \mathrm{C}\right)$ facilitating its homogenisation within the EBO. Obviously, the EBO/glutaric acid ratio has also a profound impact on the final appearance of the polymers. At that 197 stage the reaction time was increased to $16 \mathrm{~h}$ to assure as far as possible a complete 198 polymerisation. Too small quantities $(0.25,0.5$ equiv., entries $7-8)$ of glutaric acid did 199 not provide sufficient crosslinking leading to liquid or partly gel-type materials. One 200 equivalent of diacid (entry 9) provided poor crosslinking and offered a brittle polymer 
201 material. Excess of diacid (4 or 6 equiv., entries 11, 12) promoted unsatisfactory crosslinking, the reaction led to a sticky polymer material (4 equiv.) and to a sticky paste

203 (6 equiv.). The excess of carboxylic acid functions limited the crosslinking process to 204 oligomers, keeping most of the acid function untouched. Two equivalents of glutaric acid 205 were finally the best EBO/diacid ratio affording a translucent yellowish polymer (Entry $20610)$.

At a molecular level, ${ }^{1} \mathrm{H}$ NMR analysis were carried out for samples obtained with 2080.5 equiv. of glutaric acid (Table 2, entry 8) the other sample (1, 2, 4, 6 equiv., entries 9209 12) being insoluble in any common solvent tried $\left(\mathrm{CHCl}_{3}, \mathrm{THF}\right.$, toluene...). The NMR data 210 confirmed both the formation of new ester linkages and subsequent alcohol functions 211 (new signals at $4.9 \mathrm{ppm}$ and $3.5 \mathrm{ppm}$ ). It also demonstrated that the integrity of the 212 triglyceride structure is preserved. Quantitatively with 0.5 equiv. of diacid (1 COOH for 2133.9 epoxides) we observed the formation of 0.74 (maximum of 1 ) new ester linkages and 2142.6 remaining epoxides. The other reacted epoxides correspond to side reactions 215 identified by NMR to the formation of ether linkages (ring opening polymerisation of the 216 epoxide). After $16 \mathrm{~h}$ of heating this side reaction is limited to only 0.56 . Not observed for 217 the reaction carried out in solution (scheme 2) the formation of ether linkages is present 218 in bulk conditions. However, these reactions still have a lower rate compared to the 219 preferred polyester formation.

The results of the crosslinking step performed with 0.25 to 6 equivalents of 221 glutaric acid (Entry 7-12) were also analysed by ATR-FTIR spectroscopy. The stacked 222 spectra are shown in fig.2. Globally these spectra confirmed the results discussed above. 223 In more details two regions are interesting to discuss 1) the signals related to the 224 epoxide functions around $820 \mathrm{~cm}^{-1}$ and 2) the signals related to the carbonyl groups 225 between 1680 and $1750 \mathrm{~cm}^{-1}$. Within the epoxide region, the poorly polymerised 
226 material (0.25 equiv.) demonstrated the presence of residual epoxide functions, the 227 spectra being very similar to the original epoxidized oil. Increasing the number of 228 equivalent of diacid, the epoxide band disappears progressively until total 229 disappearance in the presence of 4 or 6 equivalents of diacid. Within the carbonyl region 230 (i.e. $1700 \mathrm{~cm}^{-1}$ ), several bands are visible corresponding either to acid or ester functions. 231 Again this region is very similar to the EBO spectra for the material prepared with 0.25 232 equivalent of diacid. This band corresponds mainly to the ester function of the 233 triglyceride itself. Excess of diacid (4/6 equiv.) led to the appearance of a band at lower 234 wave numbers corresponding to residual carboxylic acid groups. The polymer material 235 obtained with 2 equiv. of glutaric acid presents two ester bands distinguished by 236 different intensities, which originate from the triglyceride and from the new ester 237 functions formed during the crosslinking process. Thus these ATR-FTIR analyses 238 confirmed the degree of polymerisation obtained as a function of the quantity of diacid 239 involved in the reaction. It also confirmed that our polymers correspond mainly to 240 polyester-type materials.

\section{$241 \quad 3.4$. Crosslinking with different dicarboxylic acids}

242 The best conditions determined for glutaric acid ( 2 equiv., $120^{\circ} \mathrm{C}, 0.1$ equiv of $243 \mathrm{MeONa}$ ) were then applied to longer carboxylic diacids (C5, C6, C8, C10, C12, C14, C16) 244 and to o-phenylene diacetic acid (Scheme 3). The temperature of homogenisation was 245 adjusted for each sample as a function of the melting point of each diacid and all 246 polymerisation were carried out at $120^{\circ} \mathrm{C}$ for $16 \mathrm{~h}$ (Table 3). Whatever the diacid used 247 the polymerisation led to a yellowish translucent material (Fig.3) except for the 248 aromatic derivative, which led to a brown translucent material.

249 All polyester materials were then characterised by DMA. Fig.4 showsrepresentative 250 temperature dependence of the storage modulus ( $\left.E^{\prime}\right)$ and loss factor $(\tan \delta)$ obtained 
251 from the dynamic mechanical analyses (DMA, at a frequency of $1 \mathrm{~Hz}$ ) of networks 252 prepared in this work (EBO/glutaric acid polyester shown). The tan $\delta$ curve shows two 253 distinct peaks for all polyesters. The lower temperature peak, located at about $-75^{\circ} \mathrm{C}, \mathrm{can}$ 254 only be seen at a lower scale. It is associated with the secondary $\beta$ relaxation, which was 255 already described in epoxy resins cured with anhydride.(Boquillon and Fringant, 2000) 256 This particular secondary relaxationcorresponds to the first drop of the storage 257 modulus (fig.4) and can be more easily associated to the low temperature peak observed on fig.5 representing the temperature dependence of loss modulus (E") of EBO/glutaric acid polyester. Thissecondary $\beta$ relaxation can be associated to the motion of the diester

260 segments created between two crosslinks.(Gerbase et al., 2002)

261 The second peak of $\tan \delta$ obtained at higher temperature, between -5 and $5{ }^{\circ} \mathrm{C}(\mathrm{Fig} .4)$, 262 corresponds to the second and biggest decrease of the storage modulus and to a 263 significant second peak of loss modulus just below $0^{\circ} \mathrm{C}$. This major transition is 264 correlated to the $\alpha$ relaxation and associated to the glass transition temperature (Tg) of 265 the polymer. The $\alpha$ transition temperature is below $0^{\circ} \mathrm{C}$ (except for aromatic derivative), 266 indicating that polymers are in a rubbery state at room temperature.All data obtained by 267 DMA for all polyesters materialsaregathered in Table 4. $\alpha$ and $\beta$ relaxation temperatures 268 were recorded for each polyester sample from both tan $\delta$ peaks and loss modulus peaks.

269 It can be first noticed that increasing diacid length from five to eight carbons first caused 270 a decrease in the $\alpha$ relaxation temperature: determined from $\tan \delta$ peak, this 271 temperature dropped from -1.4 to $-4.4^{\circ} \mathrm{C}$. From loss modulus data, this temperature also 272 noticeably dropped from -5.7 to $-11,4^{\circ} \mathrm{C}$. The decrease of the $\alpha$ transition temperature, 273 which corresponds to the glass transition temperature of the polymer could be ascribed 274 to an increase in chain mobility and free volume in the polymer as the diacid length 
275

276

277

278

increased. Nevertheless, when the diacid length further increased from eight carbons to sixteen carbons, the $\alpha$ relaxation temperature gradually increased from $-4.4^{\circ} \mathrm{C}$ to $+4.4^{\circ} \mathrm{C}$ $\left(\tan \delta\right.$ ) or from $-11.4^{\circ} \mathrm{C}$ to $-2.6^{\circ} \mathrm{C}$ (loss modulus). It is well known that the crosslinks length influences glass transition temperature. In the present study, for small diacids with less than 8 carbons, the free volume of the material increased as the crosslinks length increased and the glass transition temperature decreased correspondingly (fig.6). For diacids with more than 8 carbons, the further increase in diacid length caused an increase in glass transition temperature. This could be ascribed to the longer methylene sequences in the diacids, leading to enhanced cristallinity and enhanced London dispersion interactions, resulting in stronger restriction in mobility.(Stempfle et al., 2014)This phenomenon is less clearly observed on the $\beta$ relaxation temperature, but a minimum was also recorded for suberic (C8) based polyester at $-73^{\circ} \mathrm{C}(\tan \delta$ peak) and $77^{\circ} \mathrm{C}$ (loss modulus peak). When the polyester is synthetized from $o$-phenylene diacetic acid, its $\alpha$ and $\beta$ transitions temperature, +16.2 and $-66^{\circ} \mathrm{C}$ respectively (from $\tan \delta$ ) are significantly higher than those observed for previous linear diacids. This could be correlated to the presence of aromatic crosslinks organising themselves into more rigid segments.

\section{Conclusion}

This research work demonstrates that the polymerisation of vegetable oil can be achieved following a two-step process from an extracted oil and aliphatic diacids. The epoxidation/ring opening sequence was first optimised with benzoic acid and then the best conditions (basic media) were applied to several diacids leading to the crosslinking of the triglycerides. It provides an access to original polyester materials not acquirablewith other polymerisation strategies (anhydride curing for instance). The conversion of the useless broccoli seed oil to polymer material constitutes therefore a 
300 valuable use of such non-food triglycerides. All polyesters synthesised here were in

301 rubbery state at room temperature because of their relatively low glass transition

302 temperature and they present interesting mechanical properties for numerous

303 applications. It was thus demonstrated that glass transition temperatures (Tg) and also,

304 to a lesser extend, secondary $(\beta)$ relaxations in the cured polyesters were closely related

305 to the nature and the length of the diacid used in the crosslinking reaction.

306 Such new kind of green polymers could find numerous applications in the 307 manufacture of environmentally friendly soft and flexible materials. For example, they 308 can be blended with some other polymers in order to decrease their $\mathrm{Tg}$ through 309 "permanent" plasticization. On the basis of epoxide ring opening reaction descried in 310 this paper, it will be possible to prepare new cured polymers involving other bi311 functional (or more) crosslinking agents. Some new additives could also be prepared 312 from epoxidised broccoli oil functionalization. Also it must be noticed that all the 313 chemical modifications and polymerisation processes described in this paper can be 314 applied to other type of oil.

\section{Acknowledgements}

316 The authors acknowledge the financial support of the Region Bretagne and Sojasun 317 Technologies.The authors thank Estelle Guyonvarch for the substantial experimental 318 work done on this project.

\section{References.}

320 Altuna, F.I., Espósito, L.H., Ruseckaite, R.A., Stefani, P.M., 2011. Thermal and mechanical 321 properties of anhydride-cured epoxy resins with different contents of biobased epoxidized soybean oil. J. Appl. Polym. Sci. 120, 789-798. 
323

324

325

326

327

328

Audic, J.-L., Lemiègre, L., Corre, Y.-M., 2014. Thermal and mechanical properties of a polyhydroxyalkanoate plasticized with biobased epoxidized broccoli oil. J. Appl. Polym. Sci. 131, 10.1002/app.39983.

Belgacem, M.N., Gandini, A., 2008. Monomers, Polymers and Composites from Renewable Resources. Elsevier Limited, Amsterdam.

Biermann, U., Bornscheuer, U., Meier, M.A.R., Metzger, J.O., Schäfer, H.J., 2011. Oils and Fats as Renewable Raw Materials in Chemistry. Angew. Chem. Int. Ed. 50, 38543871.

Boquillon, N., Fringant, C., 2000. Polymer networks derived from curing of epoxidized lineseed oil: influence of different catalysts and anhydride hardeners. Polymer 41, 8603-8613.

Chernykh, A., Alam, S., Jayasooriya, A., Bahr, J., Chisholm, B.J., 2013. Living carbocationic polymerization of a vinyl ether monomer derived from soybean oil, 2(vinyloxy)ethyl soyate. Green Chem. 15, 1834-1838.

España, J.M., Sánchez-Nacher, L., Boronat, T., Fombuena, V., Balart, R., 2012. Properties of Biobased Epoxy Resins from Epoxidized Soybean Oil (ESBO) Cured with Maleic Anhydride (MA). J Amer Oil Chem Soc 89, 2067-2075.

Espinoza-Perez, J.D., Nerenz, B.A., Haagenson, D.M., Chen, Z., Ulven, C.A., Wiesenborn, D.P., 2011. Comparison of curing agents for epoxidized vegetable oils applied to composites. Polymer Composites 32, 1806-1816.

Gerbase, A.E., Petzhold, C.L., Costa, A.P., 2002. Dynamic Mechanical and Thermal Behavior of Epoxy Resins Based on Soybean Oil. J. Am. Oil Chem. Soc. 79, 797-802.

Ma, Q., Liu, X., Zhang, R., Zhu, J., Jiang, Y., 2013. Synthesis and properties of full bio-based thermosetting resins from rosin acid and soybean oil: the role of rosin acid derivatives. Green Chem. 15, 1300-1310. 
348 Maisonneuve, L., Lebarbe, T., Grau, E., Cramail, H., 2013. Structure-properties relationship of fatty acid-based thermoplastics as synthetic polymer mimics. Polymer Chemistry 4, 5472-5517.

Meier, M.A.R., 2014. Sustainable polymers: reduced environmental impact, renewable raw materials and catalysis. Green Chem. 16, 1672-1672.

Meier, M.A.R., Metzger, J.O., Schubert, U.S., 2007. Plant oil renewable resources as green alternatives in polymer science. Chem. Soc. Rev. 36, 1788-1802.

Montero de Espinosa, L., Gevers, A., Woldt, B., Gra, Meier, M.A.R., 2014. Sulfur-containing fatty acid-based plasticizers via thiol-ene addition and oxidation: synthesis and evaluation in PVC formulations. Green Chem. 16, 1883-1896.

Montero de Espinosa, L., Meier, M.A.R., 2011. Plant oils: The perfect renewable resource for polymer science?! Eur. Polym. J. 47, 837-852.

Mutlu, H., Meier, M.A.R., 2010. Castor oil as a renewable resource for the chemical industry. Eur. J. Lipid Sci. Technol. 112, 10-30.

Ručigaj, A., Alič, B., Krajnc, M., Šebenik, U., 2014. Investigation of cure kinetics in a system with reactant evaporation: Epoxidized soybean oil and maleic anhydride case study. Eur. Polym. J. 52, 105-116.

Samper, M.D., Fombuena, V., Boronat, T., García-Sanoguera, D., Balart, R., 2012. Thermal and Mechanical Characterization of Epoxy Resins (ELO and ESO) Cured with Anhydrides. J Amer Oil Chem Soc 89, 1521-1528. Vegetable Oil-Based Polymers. J. Polym. Environ. 12, 173-178.

370 Shogren, R.L., 1999. Preparation and characterization of a biodegradable mulch: Paper coated with polymerized vegetable oils. J. Appl. Polym. Sci. 73, 2159-2167. 
372 Stemmelen, M., Pessel, F., Lapinte, V., Caillol, S., Habas, J.P., Robin, J.J., 2011. A fully biobased epoxy resin from vegetable oils: From the synthesis of the precursors by thiol-ene reaction to the study of the final material. Journal of Polymer Science Part A: Polymer Chemistry 49, 2434-2444.

376 Stempfle, F., Ritter, B.S., Mulhaupt, R., Mecking, S., 2014. Long-chain aliphatic polyesters from plant oils for injection molding, film extrusion and electrospinning. Green Chem. 16, 2008-2014.

Tan, S.G., Chow, W.S., 2010. Biobased Epoxidized Vegetable Oils and Its Greener Epoxy Blends: A Review. Polym.-Plast. Technol. Eng. 49, 1581-1590.

Winkler, M., Meier, M.A.R., 2014. Highly efficient oxyfunctionalization of unsaturated fatty acid esters: an attractive route for the synthesis of polyamides from renewable resources. Green Chem. 16, 1784-1788.

Xia, Y., Quirino, R.L., Larock, R.C., 2013. Bio-based Thermosetting Polymers from Vegetable Oils. J. Renew. Mater. 1, 3-27.

386 Yang, D., Peng, X., Zhong, L., Cao, X., Chen, W., Zhang, X., Liu, S., Sun, R., 2014. “Green” films from renewable resources: Properties of epoxidized soybean oil plasticized ethyl cellulose films. Carbohydr. Polym. 103, 198-206. 